\title{
Catalytic Removal of Toluene from Air Streams by Cobalt Oxide Supported on Sepiolite
}

\author{
Mahdi B. Ardakani, ${ }^{a}$ Hasan A. Mahabadi ${ }^{\odot *, a}$ and Ahmad J. Jafari ${ }^{b}$ \\ ${ }^{a}$ Occupational Health Engineering Department, Faculty of Medical Sciences, \\ Tarbiat Modares University, Jalal Ale Ahmad Highway, 14115-111 Tehran, Islamic Republic of Iran \\ ${ }^{b}$ Research Center for Environmental Health Technology, Iran University of Medical Sciences, \\ Shahid Hemmat Highway, 14665-354 Tehran, Islamic Republic of Iran
}

\begin{abstract}
Removal of toluene using cobalt oxide supported on sepiolite catalysts was investigated. Deposition precipitation method was used to prepare the catalysts. The catalysts were characterized using X-ray diffraction, field emission scanning electron microscopy, energy dispersive X-ray spectroscopy, thermogravimetric analysis (TGA) and Brunauer-Emmet-Teller methods. The results of catalytic testing showed that $20 \%$ cobalt oxide/sepiolite (Co20/Sep) had higher catalytic activity for degradation of toluene. A temperature of $400{ }^{\circ} \mathrm{C}$ was found to be the optimum calcination temperature for Co20/Sep, since it achieved $90 \%$ toluene conversion at about $300{ }^{\circ} \mathrm{C}$. The results showed that the selectivity of the catalysts towards $\mathrm{CO}_{2}$ was complete and no byproducts were detected. Stability tests also indicated that Co20/Sep remains stable at $320{ }^{\circ} \mathrm{C}$ with complete conversion of toluene after $24 \mathrm{~h}$. In conclusion, the results of this study confirmed sepiolitesupported cobalt oxide catalyst as an efficient catalyst for degradation of toluene.
\end{abstract}

Keywords: sepiolite, cobalt oxide, toluene, catalytic degradation

\section{Introduction}

Air pollution is one of the fundamental health problems which accounts for more than seven million deaths annually. ${ }^{1}$ Volatile organic compounds (VOCs) are considered as the main contributors of air pollution. ${ }^{2,3}$ VOCs are typically released into the air from automobile industries, fuel combustions, chemical industries, cleaning products, decomposition in the biosphere and biomass, petroleum refineries, pharmaceutical plants, solvents processes, printers, etc. ${ }^{4}$ Aromatic compounds, including VOCs, are toxic and carcinogenic. ${ }^{5}$ In addition, they may harm respiratory, nervous, digestion, and metabolic systems, pose mutagenic hazards, and cause environmental issues such as ozone depletion, photochemical smog, and particulate matter (PM) formation. ${ }^{6,7}$ At lower than $100 \mathrm{ppm}$ concentrations, VOCs can cause nausea, loss of appetite, memory and sight, and tiredness. Exposure to high levels of aromatic compounds through inhalation can cause dizziness, unconsciousness, and even death. ${ }^{8,9}$

*e-mail: asilia_h@modares.ac.ir
Considering the environmental and health related problems of VOCs, it is necessary to develop effective and efficient technologies to control VOCs emissions. ${ }^{10}$ For effective VOCs removal from gas streams, various methods and techniques such as absorption, adsorption, biological degradation, catalytic oxidation, condensation, thermal incineration, and photocatalytic oxidation have been developed. ${ }^{11-13}$ However, most of the control techniques have their defects and limitations for practical application. For example, thermal incineration method requires fuel and temperature resistant materials and involves explosion hazard. In addition, it may produce hazardous byproducts such as carbon monoxide and dioxins in the incinerator exhaust gas. ${ }^{14}$ Therefore, development of an efficient and cost-effective technique for VOCs removal and converting them to less harmful products such as $\mathrm{CO}_{2}$ and $\mathrm{H}_{2} \mathrm{O}$ is essential. ${ }^{15,16}$

Catalytic oxidation is considered as an efficient technique for VOCs removal and is mainly divided into two categories: noble metal catalysis and metal oxide/transition metal catalysis. ${ }^{17}$ Noble metal catalysis is eminent for its high activity and stability, ${ }^{18-20}$ however, its high cost and also the sensitivity to poisons limit the noble metal catalysis 
applications..$^{21,22}$ On the other hand, metal oxide/transition metal catalysts are more stable against poisons and they are less expensive, but they typically have lower activity than noble metal catalysts. ${ }^{23}$

For catalytic oxidation and removal of VOCs, metal oxides including copper oxide, chromium oxide, iron oxide, magnesium oxide, manganese dioxide, nickel oxide, and cobalt oxide $\left(\mathrm{Co}_{3} \mathrm{O}_{4}\right)$ have been successfully applied. ${ }^{24}$ Cobalt catalysts, due to the existence of mobile oxygen in their spinel type structure, have been used efficiently in a wide range of reactions. ${ }^{25,26}$ The noticeable efficiency of $\mathrm{Co}_{3} \mathrm{O}_{4}$ in the VOCs removal is due to its high oxygen vacancies and reduction capacity as well as the high concentration of electrophilic oxide species, generated by the relatively low $\mathrm{Co}-\mathrm{O}$ bond energy, which facilitates the interaction between the reactants and the oxygen atoms in the lattice. ${ }^{17,27}$ However, its activity depends, among other factors, on the preparation conditions, the crystallization level, the cobalt oxidation state, and the surface area of the material. ${ }^{15}$

Metal oxide catalysts can be either unsupported or supported by different materials such as aluminum oxide, zeolite, and diatomite. Due to the higher dispersion of the active components, the supported catalysts have higher efficiency in the oxidation and removal of VOCs. Recently, researchers have focused on the porous adsorbent materials as metal oxide supports for production of catalysts. Some of the most commonly used porous materials are activated carbon, ${ }^{28}$ alumina, ${ }^{29}$ diatomite, ${ }^{30}$ silica $^{31}$ and zeolite. ${ }^{32}$

Sepiolite is a member of clay mineral family with the formula of $\mathrm{Mg}_{8} \mathrm{Si}_{12} \mathrm{O}_{30}(\mathrm{OH})_{4} \cdot 4 \mathrm{H}_{2} \mathrm{O} \cdot \mathrm{nH}_{2} \mathrm{O}$. It is an inexpensive hydrated magnesium silicate which has a fibrous structure with uniform size parallel-piped intra crystalline tunnels along the fibers. This tunnel structure results in high porosity and huge specific surface area of sepiolite, which can provide more reaction sites for various cations to be substituted with the magnesium ions on the tunnel surface.

Sepiolite, as a catalyst support, has been investigated by some researchers. For example Güngör et $a l .{ }^{33}$ used it as a silver support in combustion of soot. In 2010, a sepiolite based catalyst support was synthesized by Milt et al. ${ }^{34}$ for removal of diesel exhaust pollutants. Liu et al. ${ }^{35}$ also introduced a Ni and Mo supported sepiolite catalyst for steam reforming reactions. Likewise, Bautista et al. ${ }^{36}$ studied sepiolite and $\mathrm{TiO}_{2}$ supported vanadium oxide catalysts for removal of toluene from aqueous streams.

Since, up to our knowledge, no research has addressed the removal of toluene using sepiolite-supported cobalt oxide catalyst; this study was conducted to evaluate the effectiveness of sepiolite-supported cobalt oxide catalyst in degradation of toluene in air streams.

\section{Experimental}

\section{Materials}

Natural sepiolite was obtained from Dorkav mine in North khorasn, Iran. Ammonium nitrate $\left(\mathrm{NH}_{4} \mathrm{NO}_{3}\right)$, toluene, cobalt nitrate, and sodium bicarbonate $\left(\mathrm{NaHCO}_{3}\right)$ were purchased from Merck Company (Germany).

\section{Synthesis}

Raw sepiolite was crushed and sieved to obtain a particle size of 0.425-0.840 mm (mesh 20-40), washed several times using deionized water and then dried at $110{ }^{\circ} \mathrm{C}$ for $24 \mathrm{~h}$. Then, the product was mixed with $\mathrm{NH}_{4} \mathrm{NO}_{3}$ solution at a ratio of $10 \mathrm{~mL} \mathrm{NH}_{4} \mathrm{NO}_{3}$ solution per $\mathrm{g}$ sepilolie. The obtained mixture was heated and stirred for $8 \mathrm{~h}$ at $80^{\circ} \mathrm{C}$. Then, it was filtered and washed by deionized-water until its $\mathrm{pH}$ reached to 7. After that, the mixture was dried at $110^{\circ} \mathrm{C}$ for $24 \mathrm{~h}$. A nitrate solution was prepared by addition of deionized water to $\mathrm{Co}\left(\mathrm{NO}_{3}\right)_{2} \cdot 6 \mathrm{H}_{2} \mathrm{O}$. Deposition-precipitation was performed for $9 \mathrm{~h}$ by mixing and heating at $70-80{ }^{\circ} \mathrm{C}$ and metal ions were precipitated on the sieved treated sepiolite by adding a solution of $\mathrm{NaHCO}_{3}\left(1 \mathrm{~mol} \mathrm{~L}^{-1}\right)$ in 30 min intervals until reaching a basic solution with a $\mathrm{pH}$ of $10-11$ to obtain 5,10 , 15 and $20 \mathrm{wt} . \%$ metal loadings. To separate the catalyst, the basic solution was filtered. Then, the catalyst sample was washed several times by heated deionized water. Afterwards, the sample was dried at $110^{\circ} \mathrm{C}$ in an oven, overnight. The dried catalyst was calcinated in a furnace for $4 \mathrm{~h}$ at a heating rate of $5{ }^{\circ} \mathrm{C} \mathrm{min}-1$ from room temperature to 400,500 and $600^{\circ} \mathrm{C}$. Prepared catalysts were symbolized by metal content of the support $[\mathrm{x}(\mathrm{wt} \%)] \mathrm{Co} /$ sepiolite $(\mathrm{x}=5,10,15$ and 20$)$. For example, the catalyst with $5 \mathrm{wt} . \%$ Co supported on sepiolite was named Co5/Sep.

\section{Characterization methods}

Power X-ray diffraction patterns (XRD) of catalysts were recorded using a Philips pw1730 diffractometer (Netherlands) with a radiation source of $\mathrm{Cu}-\mathrm{K} \alpha$ $(\lambda=1.5406 \AA)$ and operated at $40 \mathrm{~V}$ and $30 \mathrm{~mA}$. X-ray diffraction data were collected with the $2 \theta$ range from 4 to $80^{\circ}$ with a step interval of $0.05^{\circ}$.

The contents of cobalt on the catalysts were measured by inductively coupled plasma optical emission spectroscopy (ICP-OES) technique using a VISTA-PRO (Varian Inc., USA). 
Micromeritics TriStar instrument (Micromeritics, Norcross, USA) was used to measure micro pore and Brunauer-Emmett-Teller (BET) surface area, in this regard, $\mathrm{N}_{2}$ was used as an adsorbent gas at $77 \mathrm{~K}$. To eliminate surface water, samples were degassed at $130{ }^{\circ} \mathrm{C}$ for $25 \mathrm{~min}$ and then at $300{ }^{\circ} \mathrm{C}$ for $4 \mathrm{~h}$ under vacuum. Using the adsorption isotherm data and the BET equation in the range of $\mathrm{p} / \mathrm{p} 0$ from 0.05 to 0.35 , the specific surface area was calculated. The total pore volumes were determined at $\mathrm{p} / \mathrm{p} 0=0.95$. Pore size distribution was calculated using the Barrett-Joyner-Halenda (BJH) formula from the desorption branches of the $\mathrm{N}_{2}$ adsorption isotherms.

Coke content of the catalyst was measured by thermogravimetric analysis (TGA) using a TGA7 thermogravimetry analyzer (PerkinElmer, USA) under air and a heating rate of $10{ }^{\circ} \mathrm{C} \mathrm{min}^{-1}$.

The particle size and surface morphology were evaluated using a field emission scanning electron microscope (FESEM) model TESCAN MIRAii, Czech, at an acceleration voltage of $15 \mathrm{kV}$. The surface elemental compositions were determined by energy-dispersive $\mathrm{X}$-ray spectroscopy (EDS) coupled with FESEM.

\section{Catalytic evaluation}

The catalytic performance was measured by a fixed bed reactor (stainless steel $10 \mathrm{~mm}$ diameter and $100 \mathrm{~mm}$ length) which functions in continuous air flow at atmospheric pressure. Figure 1 shows the layout of the catalyst system. The catalytic degradation was studied as a temperature function. In this regard, a total flow of $500 \mathrm{~mL} \mathrm{~min}^{-1}$ and
$0.500 \mathrm{~g}$ of 0.841-0.420 mm (mesh 20-40) cobalt/sepiolite catalyst corresponding to gas hourly space velocity (GHSV) of $60000 \mathrm{~cm}^{3} \mathrm{~g}^{-1} \mathrm{~h}^{-1}$, treated atmospheric air as an oxidizing agent, and a toluene concentration of 1000 ppm, supplied by a permeable unit were used. The catalyst was pretreated in air flow at $350^{\circ} \mathrm{C}$ for $1.5 \mathrm{~h}$.

The catalytic performance was at temperatures of 100 to $400{ }^{\circ} \mathrm{C}$. Concentration of toluene at the inlet and outlet of the reactor was determined using an Ion Science Phocheck Tiger with a photoionization detector (PID) detector (Ion Science, UK). To measure the intermediate and byproducts of toluene degration, an Agilent (USA) GC-MS (gas chromatography mass spectrometer) equipped with a 5975 mass detector and an HP-5ms column was used according to relevant literature. ${ }^{29,30}$ The concentration of the produced $\mathrm{CO}_{2}$ and $\mathrm{CO}$ were measured using a non dispersive infrared sensor (AQ $110 \mathrm{Kimo}$ ) and a portable $\mathrm{CO}$ sensor (Kimo), respectively. Each experiment was repeated three times, and the average of the results was determined.

Equations 1 and 2 were used to calculate the removal efficiency of toluene and $\mathrm{CO}_{2}$ yield, respectively:

$$
\begin{aligned}
& \eta(\%)=\frac{[\text { Toluene }] \text { in }-[\text { Toluene }] \text { out }}{[\text { Toluene }] \text { in }} \times 100 \\
& \mathrm{CO}_{2} \text { yield }(\%)=\frac{\left[\mathrm{CO}_{2}\right] \text { out }}{7[\text { Toluene }] \text { in }} \times 100
\end{aligned}
$$

where, [Toluene]in and [Toluene]out are, respectively, the concentrations of toluene in the inlet and outlet of the reactor

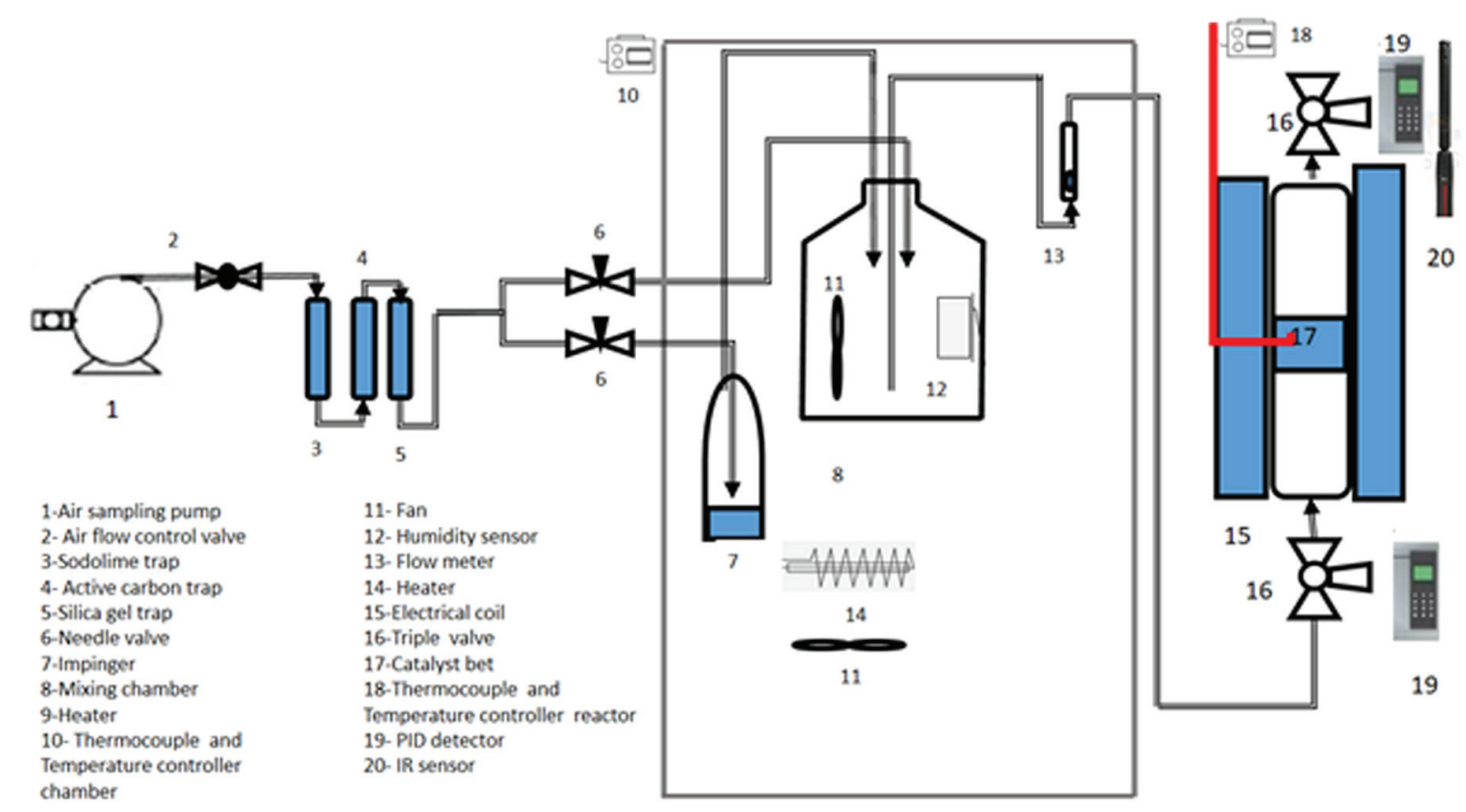

Figure 1. Experimental system for catalytic degradation of toluene. 
and 7 is the carbon number of toluene molecule. $\left[\mathrm{CO}_{2}\right]$ out is the $\mathrm{CO}_{2}$ concentration at the outlet of the reactor.

\section{Results and Discussion}

\section{Characterization of catalysts}

The XRD patterns of sepiolite, $\mathrm{NH}_{4} \mathrm{NO}_{3} / \mathrm{Sep}$, and $\mathrm{Co} / \mathrm{Sep}$ samples are presented in Figure 2. For sepiolite support, the diffraction peaks were detected only at 7 , 19 , and $26.52 \theta$. For the samples with deposited cobalt, besides the peaks of sepiolite, diffraction peaks were observed at $37.9,60$, and $66.82 \theta$ assigned to crystalline $\mathrm{Co}_{3} \mathrm{O}_{4}$ (JPCDS 01-074-1656). This part of our findings is supported by Rokicińska et al..$^{22}$ study, which reported nearly similar angles of diffraction for crystalline $\mathrm{Co}_{3} \mathrm{O}_{4}$ on zeolite at $36.8,59.4$ and $65.3^{\circ}$.

The average particle size of the cobalt oxide was calculated using Scherrer formula, $\mathrm{L}=\frac{\mathrm{K} \lambda}{\beta \cos \alpha}$. In this formula, $\mathrm{L}$ is the crystallite size, $\mathrm{K}$ is a constant related to crystallite shape, $\lambda$ is the wavelength of the $\mathrm{X}$-ray source $(0.15406 \mathrm{~nm}), \beta$ is the full width half maximum (FWHM), and $\alpha$ is the angle of diffraction. According to the formula, the average size of the cobalt oxide particles was $52 \mathrm{~nm}$.

The BET surface area, porous volume, and average pore diameter of the sepiolite and the catalysts are summarized in

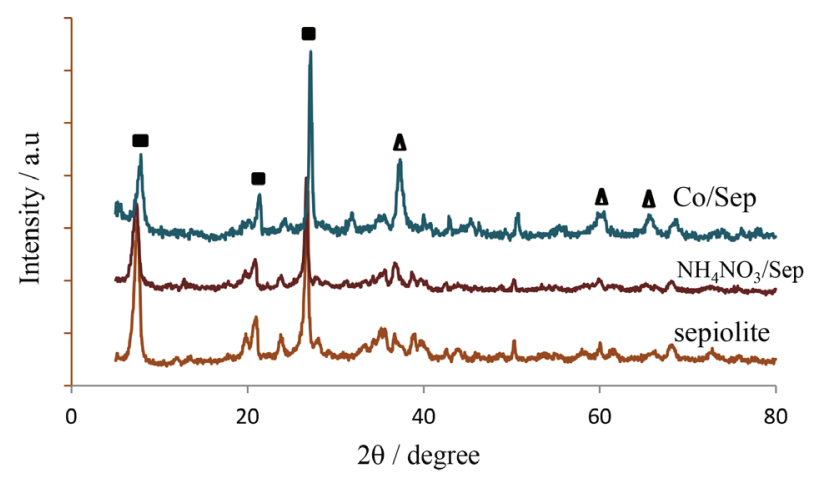

Figure 2. XRD patterns of sepiolite, $\mathrm{NH}_{4} \mathrm{NO}_{3} / \mathrm{Sep}$, and the sepiolite samples after deposition of cobalt ( $\boldsymbol{\square}$ : sepiolite; $\left.\boldsymbol{\Delta}: \mathrm{Co}_{3} \mathrm{O}_{4}\right)$.
Table 1. Figure 3 shows $\mathrm{N}_{2}$ adsorption desorption isotherms and pore size distributions of sepiolite, $\mathrm{NH}_{4} \mathrm{NO}_{3} / \mathrm{Sep}$, and cobalt oxide/sepiolite samples. As this figure shows, all samples exhibit a type IV isotherm, and obvious hysteresis loops are observed, indicating the formation of mesoporous material. The BET surface area and the total pore volume of the sepiloite showed the following order: $\mathrm{NH}_{4} \mathrm{NO}_{3} / \mathrm{Sep}>$ sepiolite $>$ Co20/Sep $>$ Co15/Sep $>$ Co5/Sep $>$ Co10/Sep (Table 1). These reductions in total pore volume and surface area has been reported by other researchers and has been attributed to the filling of the sepiolite pores with metal particles. ${ }^{37,38}$

Field emission scanning electron microscopy (FESEM) was used to examine the morphology and distribution of the catalyst. The results of FESEM are shown in Figure 4 As Figure 4 indicates, sepiolite is consisted of bundles of fibers with a diameter of around $0.2 \mu \mathrm{m}$ and a length of up to $3 \mu \mathrm{m}$. This finding is in agreement with Zhou et al. ${ }^{39}$ Figure 3 also indicates that treatment with $\mathrm{NH}_{4} \mathrm{NO}_{3}$ has increased the sepiolite pores. BET analysis also confirmed that sepiolite pores have been increased as a result of $\mathrm{NH}_{4} \mathrm{NO}_{3}$ treatment (Table 1). The element distribution and morphologies of cobalt oxide on sepiolite can be observed in Figure 4c. According to this figure, cobalt oxide particles are homogenous and dispersed and have a spherical form. Particle size of cobalt oxide is 50-200 nm (Figure 4c). This finding approves the results obtained from Scherrer formula.

\section{Catalytic activity}

In catalytic oxidation of VOCs, the reaction temperature at the catalyst bed is the most critical parameter. To evaluate the catalytic activities of four catalysts (Co5/Sep, Co10/Sep, Co15/Sep, and Co20/Sep) for toluene removal at different temperatures, the oxidation of toluene, with the inlet concentration of $1000 \mathrm{ppm}$ and GHSV of $60000 \mathrm{~cm}^{3} \mathrm{~g}^{-1} \mathrm{~h}^{-1}$, was tested at $100-400{ }^{\circ} \mathrm{C}$ temperature range. The removal efficiencies of toluene at different reaction temperatures and different cobalt loads are shown in Figure 5. According to this figure, increasing the temperature adds the efficiency

Table 1. The BET surface area, porous volume, average pore diameter of the sepiolite, and real cobalt content of the catalysts

\begin{tabular}{lccc}
\hline Catalyst & $\begin{array}{c}\text { Specific surface } \\
\text { area (BET) / }\left(\mathrm{cm}^{2} \mathrm{~g}^{-1}\right)\end{array}$ & $\begin{array}{c}\text { Total pore volume / } \\
\left(\mathrm{cm}^{3} \mathrm{~g}^{-1}\right)\end{array}$ & $\begin{array}{c}\text { Average pore size / nm } \\
\text { Sepiolite }\end{array}$ \\
$\mathrm{NH}_{4} \mathrm{NO}_{3} / \mathrm{Sep}$ & 116 & 0.18 & 6 \\
$\mathrm{Co5} / \mathrm{Sep}$ & 195 & 0.24 & 5 \\
Co10/Sep & 52 & 0.16 & 12 \\
Co15/Sep & 43 & 0.11 & 10 \\
Co20/Sep & 77 & 0.22 & 12 \\
\hline
\end{tabular}

${ }^{\mathrm{a}}$ Measured by the ICP-AES (inductive coupled plasma atomic emission spectroscopy) technique; BET: Brunauer-Emmet-Teller; Sep: sepiolite. 

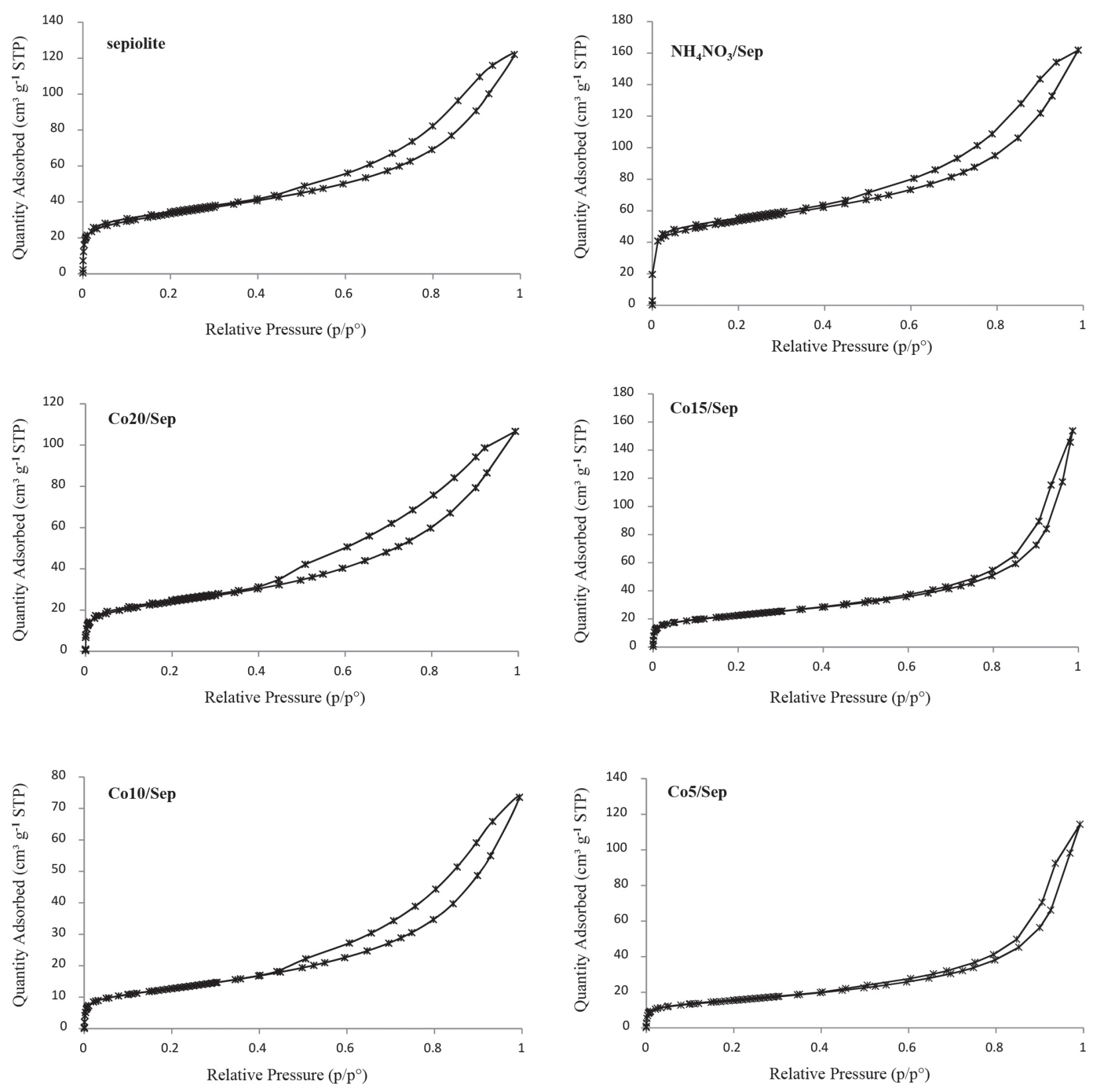

Figure 3. $\mathrm{N}_{2}$ adsorption-desorption isotherms of catalysts.

of toluene removal which can be explained by the fact that increasing the temperature provides more energy for molecules which results in more collisions. In this regard, the reaction temperature corresponding to $90 \%$ toluene conversion $\left(\mathrm{T}_{90}\right)$ for Co5/Sep, Co10/Sep, Co15/Sep, and Co20/Sep was $380,349,310$ and $300{ }^{\circ} \mathrm{C}$, respectively. In addition, the reaction temperature corresponding to $50 \%$ toluene conversion $\left(\mathrm{T}_{50}\right.$ ) for Co5/Sep, Co10/Sep, Co15/Sep, and Co20/Sep was 356, 307, 280 and $276^{\circ} \mathrm{C}$, respectively. Considering the cobalt loading, increasing the cobalt loading from 5 to $15 \%$, increases the removal efficiency of toluene, which indicates that high loading of cobalt can significantly improve the efficiency of the catalyst. But further increase in the cobalt loading did not enhance the catalytic efficiency, so that Co15/Sep exhibited similar catalytic activity for toluene degradation with that of Co20/ Sep. This finding is in agreement with Luo et al. ${ }^{40}$ study which reported that increasing the cobalt loading from 5 to $10 \%$ will enhance the catalytic efficiency of the catalyst with no enhancement in higher than $10 \%$ cobalt loadings.

Table 2 makes a comparison on the catalytic activity of Co20/Sep in $\mathrm{T}_{50}$ and $\mathrm{T}_{90}$ with cobalt catalysts on different supports for removal of toluene reported by other researchers. According to this table, catalytic activity of Co20/Sep for toluene degradation in this work is comparable with Au-Co/SBA15 (Santa Barbara Amorphous-15) and it is 

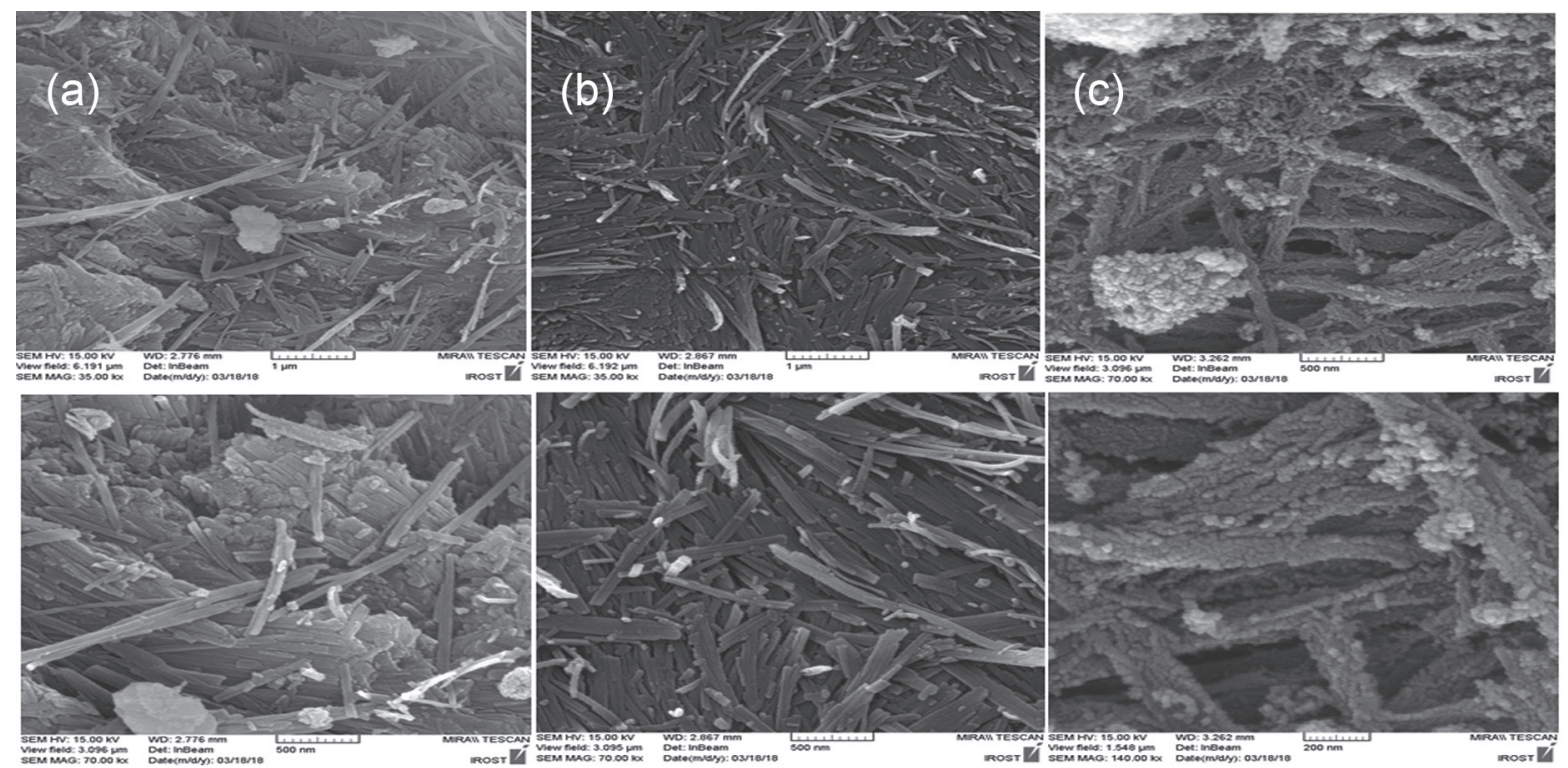

Figure 4. Image of FESEM of the catalysts (a) sepiolite; (b) $\mathrm{NH}_{4} \mathrm{NO}_{3} / \mathrm{Sep}$; (c) Co/Sep.

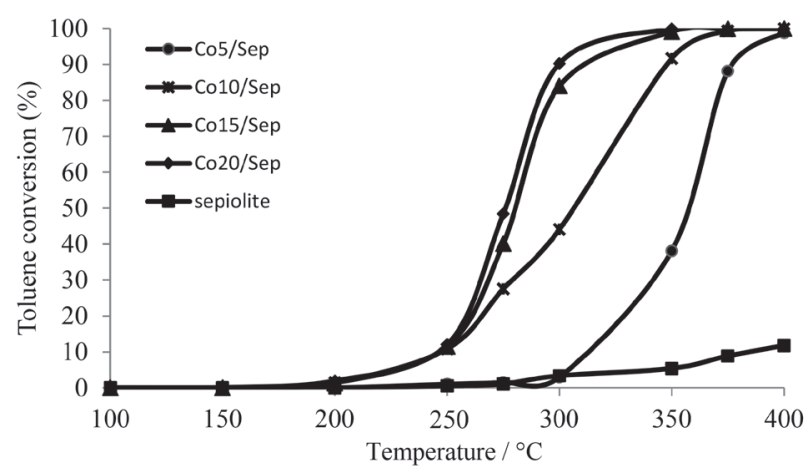

Figure 5. The removal efficiencies of toluene at different cobalt loadings.

higher than those of $\mathrm{Co} 20 / \gamma \mathrm{Al}_{2} \mathrm{O}_{3}-\mathrm{CeO}_{2}, \mathrm{Co} /$ halloysite, $\mathrm{Co} /$ beta zeolite, and $\mathrm{Co}-\mathrm{Al} / \mathrm{hydrotalcite}$. It can be also found from Table 2 that catalytic activity of Co20/Sep for toluene removal is less than $\mathrm{Co} / \mathrm{AC}$ (activated charcoal) and $\mathrm{Co} /$
$\mathrm{C}_{3} \mathrm{~N}_{4}$ which can be due to lower GHSV and toluene inlet concentration in the case of $\mathrm{Co} / \mathrm{AC}$ and $\mathrm{Co} / \mathrm{C}_{3} \mathrm{~N}_{4}$ catalysts. This study results also showed that bare sepiolite had no significant catalytic activity for removal of toluene, so that its removal efficiency was less than $10 \%$ at $400{ }^{\circ} \mathrm{C}$. This finding is parallel with the results of the studies which have examined the catalytic activity of sepiolite for degradation of different pollutants. ${ }^{33,34,45}$

The application potential of oxidative catalysts is mainly influenced by the stability of the catalysts. Therefore this study evaluated the stability of Co20/Sep at $320^{\circ} \mathrm{C}$ during $24 \mathrm{~h}$ for $1000 \mathrm{ppm}$ inlet toluene concentration with the results shown in Figure 6. The stability test showed that the toluene conversion is constant during the test period. Therefore it can be concluded that sepiolite-supported cobalt has high catalytic stability when applied for degradation of toluene.

Table 2. Comparison of the catalytic activity of different catalysts for degration of toluene

\begin{tabular}{|c|c|c|c|c|c|c|c|}
\hline \multirow{2}{*}{ No. } & \multirow{2}{*}{ Catalyst } & \multirow{2}{*}{$\mathrm{BET} /\left(\mathrm{m}^{2} \mathrm{~g}^{-1}\right)$} & \multirow{2}{*}{$\begin{array}{c}\text { GHSV / } \\
\left(\mathrm{cm}^{3} \mathrm{~g}^{-1} \mathrm{~h}^{-1}\right)\end{array}$} & \multirow{2}{*}{$\begin{array}{c}\text { Concentration / } \\
\text { ppm }\end{array}$} & \multicolumn{2}{|c|}{ Conversion temperature $/{ }^{\circ} \mathrm{C}$} & \multirow{2}{*}{ Reference } \\
\hline & & & & & $\mathrm{T}_{50}{ }^{\mathrm{a}}$ & $\mathrm{T}_{90}^{\mathrm{b}}$ & \\
\hline 1 & Co20/Sep & 82 & 60000 & 1000 & 276 & 300 & this work \\
\hline 2 & $\mathrm{Co}_{3} \mathrm{O}_{4} /$ montmorillonite & 98 & 60000 & 1000 & 285 & 297 & Rokicińska et al. ${ }^{27}$ \\
\hline 3 & $\mathrm{Co} 20 / \gamma \mathrm{Al}_{2} \mathrm{O}_{3} \mathrm{CeO}_{2}$ & 65 & 12000 & $\begin{array}{c}2.5 \mathrm{~g} \mathrm{~m}^{-3} \\
(660 \mathrm{ppm})\end{array}$ & $200 \mathrm{~T}_{70}$ & 350 & Balzer et al..$^{41}$ \\
\hline 4 & Co/halloysite & 30 & 30000 & 600 & 300 & 320 & Carrillo et al..$^{15}$ \\
\hline 5 & Co/beta zeolite & 510 & 30000 & 1000 & 300 & 325 & Rokicińska et al..$^{22}$ \\
\hline 6 & Co-Al/hydrotalcite & 72 & 60000 & 1000 & 257 & 285 & Białas et al..$^{42}$ \\
\hline 7 & $\mathrm{Co} / \mathrm{AC}$ & - & 18000 & 400 & 260 & 287 & Liao et al. ${ }^{21}$ \\
\hline 8 & $\mathrm{Co}_{3} \mathrm{O}_{4} / \mathrm{Al}_{2} \mathrm{O}_{3}$ & - & 60000 & 2000 & 313 & 322 & Zhao et al..$^{43}$ \\
\hline 9 & $\mathrm{Au}-\mathrm{Co} / \mathrm{SBA} 15$ & 222 & 30000 & 1100 & 280 & 300 & Wu et al..$^{44}$ \\
\hline 10 & $\mathrm{CoOx} / \mathrm{g}-\mathrm{C}_{3} \mathrm{~N}_{4}$ & 50 & 10000 & 1000 & 268 & 279 & Luo et al. ${ }^{40}$ \\
\hline
\end{tabular}

a,b50 and 90\% toluene conversion, respectively; BET: Brunauer-Emmet-Teller; GHSV: gas hourly space velocity; Sep: sepiolite; AC: activated charcoal; SBA15: Santa Barbara Amorphous-15. 


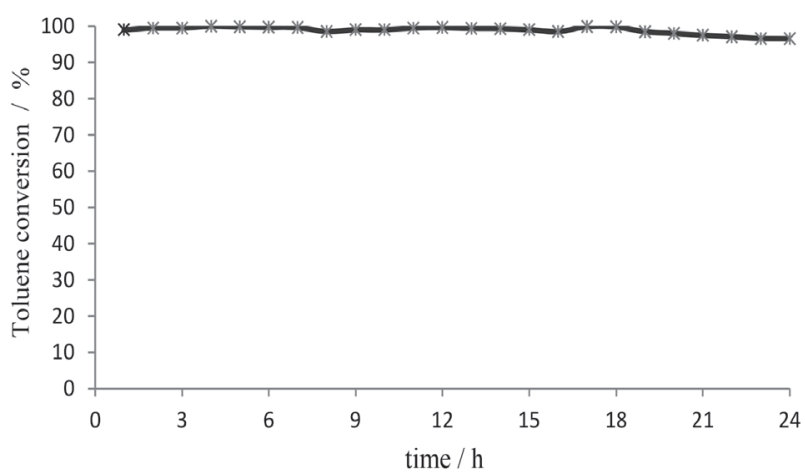

Figure 6. Toluene conversion using Co20/Sep catalyst at $320{ }^{\circ} \mathrm{C}$ as a function of time.

Calcination temperature is one of the most important factors which has a great influence on the catalytic activities of catalysts. The catalytic performance of Co20/Sep with different calcination temperatures $\left(400,500\right.$, and $\left.600^{\circ} \mathrm{C}\right)$ is shown in Figure 7. According to this figure, Co20/Sep calcined at $400{ }^{\circ} \mathrm{C}$ exhibits the highest performance, achieving $\mathrm{T}_{90}$ at about $300{ }^{\circ} \mathrm{C}$ which is $50{ }^{\circ} \mathrm{C}$ lower than that achieved by the obtained catalyst at $600^{\circ} \mathrm{C}$ calcination temperature. This decrease in catalytic performance can be due to the conversion of $\mathrm{Co}_{3} \mathrm{O}_{4}$ to $\mathrm{CoO}\left(\right.$ at $600{ }^{\circ} \mathrm{C}$ ) which has lower the catalytic activity. ${ }^{46}$ This decrease in the catalytic performance can also be linked to the grain growth caused by the thermal treatment. Yan et al. ${ }^{47}$ also reported that with increasing the calcination temperature, the catalytic activity of the catalysts is declined and the highest catalytic performance of $\mathrm{Co}_{3} \mathrm{O}_{4}$ for removal of toluene was found to be at $400{ }^{\circ} \mathrm{C}$. Despite our findings de Rivas et al.$^{48}$ reported optimum calcination temperature of $\mathrm{Co}_{3} \mathrm{O}_{4}$ for degradation of VOCs at $500{ }^{\circ} \mathrm{C}$.

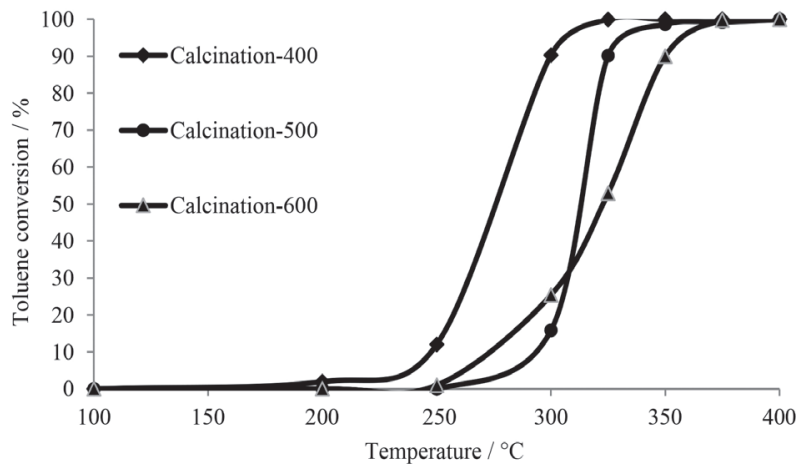

Figure 7. Catalytic performance of Co20/Sep with different calcination temperatures.

Figure 8 shows the $\mathrm{CO}_{2}$ yield $v s$. reaction temperature over cobalt oxide/sepiolite catalysts. According to this figure, when using Co15/Sep and Co20/Sep, $\mathrm{CO}_{2}$ balance is achieved at $350{ }^{\circ} \mathrm{C}$.

To measure the intermediate and byproducts of

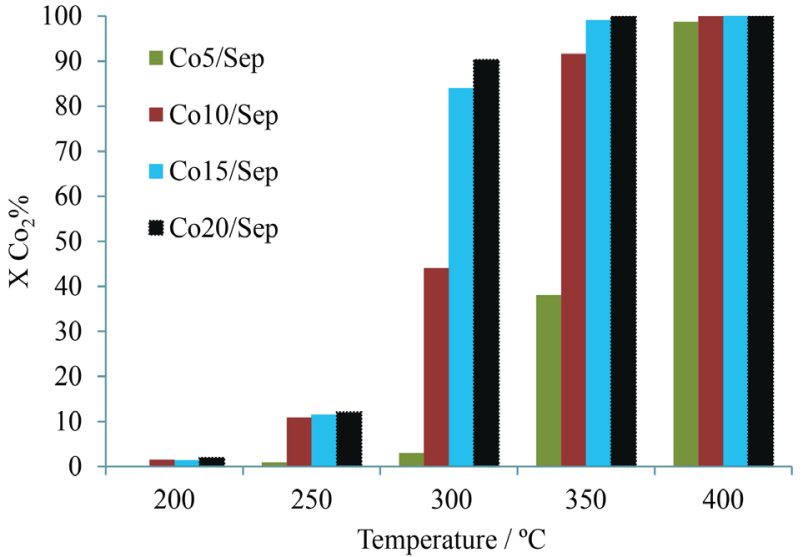

Figure 8. $\mathrm{CO}_{2}$ yield versus reaction temperature at different cobalt loadings.

toluene degration by cobalt oxide/sepiolite catalyst, GC-MS was used according to relevant literature. ${ }^{29,30}$ The results showed that at $320{ }^{\circ} \mathrm{C}$ and $99.7 \%$ removal efficiency for $1000 \mathrm{ppm}$ inlet toluene concentration, there was only a toluene peak in the sampled outlet stream with a concentration of $3 \mathrm{ppm}$ and no $\mathrm{CO}$ or any other hydrocarbons indicating that toluene was efficiently degraded to $\mathrm{CO}_{2}$ at the surface of cobalt oxide/sepiolite catalyst.

The results of TGA analysis showed that the difference between the weight losses of fresh and used catalysts was negligible, confirming no coke formation during catalytic combustion of toluene over Co20/Sep.

\section{Conclusions}

The results of this study showed that increasing the cobalt loading from 5 to $15 \%$, increases the removal efficiency of toluene, which indicates that increasing the loading of cobalt can significantly improve the efficiency of the catalyst. But further increase in the cobalt loading did not enhance the catalytic activity. A temperature of $400^{\circ} \mathrm{C}$ was found to be the optimum calcination temperature for Co20/Sep, since it achieved $90 \%$ toluene conversion at about $300{ }^{\circ} \mathrm{C}$. The results also confirmed that Co20/Sep has a high selectivity towards $\mathrm{CO}_{2}$ and it is stable at $320^{\circ} \mathrm{C}$ with complete conversion of toluene after $24 \mathrm{~h}$. In conclusion, the results of this study confirmed sepiolitesupported cobalt oxide catalyst as an efficient catalyst for degradation of toluene.

\section{Acknowledgments}

The authors appreciate the Deputy of Research and Technology of Tarbiat Modares University for its instrumental and financial supports. This study was 
conducted by the first author as part of the requirement to attain a PhD at Tarbiat Modares University, Tehran, Iran.

\section{References}

1. https://www.who.int/mediacentre/news/releases/2014/airpollution/en, accessed in April 2019.

2. Colman Lerner, J. E.; Sanchez, E. Y.; Sambeth, J. E.; Porta, A. A.; Atmos. Environ. 2012, 55, 440.

3. Peng, Y.; Zhang, L.; Chen, L.; Yuan, D.; Wang, G.; Meng, X.; Xiao, F. S.; Catal. Today 2017, 297, 182.

4. Cecchini, J. P.; Serra, R. M.; Barrientos, C. M.; Ulla, M. A.; Galván, M. V.; Milt, V. G.; Microporous Mesoporous Mater. 2011, 145, 51.

5. Zare, M.; Shahtaheri, S. J.; Mehdipur, P.; Abedinejad, M.; Zare, S.; Mol. Cell. Toxicol. 2013, 9, 303.

6. Brown, S.; Sim, M. R.; Abramson, M. J.; Gray, C. N.; Indoor Air 1994, 4, 123.

7. Zare, M.; Shahtaheri, S. J.; Mehdipur, P.; Abedinejad, M.; Zare, S.; Toxicol. Environ. Chem. 2013, 95, 187.

8. Rumchev, K.; Brown, H.; Spickett, J.; Rev. Environ. Health 2007, 22, 39.

9. http://www.euro.who.int/_data/assets/pdf_file/0009/128169/ e94535.pdf, accessed in April 2019.

10. Zhang, C.; Huang, H.; Li, G.; Wang, L.; Song, L.; Li, X.; Catal. Today 2019, 327, 374.

11. Amin, M. M.; Rahimi, A.; Bina, B.; Nourmoradi, H.; Hassanvand, M. S.; Mohammadi-Moghadam, F.; Norouzi, S.; Heidari, M.; Process Saf. Environ. Prot. 2017, 107, 508.

12. Pham, T. D.; Lee, B. K.; J. Hazard. Mater. 2015, 493, 493.

13. Jafari, S.; Ghorbani-Shahna, F.; Bahrami, A.; Kazemian, H.; Microporous Mesoporous Mater. 2018, 268, 58.

14. Kamal, M. S.; Razzak, S. A.; Hossain, M. M.; Atmos. Environ. 2016, $140,117$.

15. Carrillo, A. M.; Carriazo, J. G.; Appl. Catal., A 2015, 164, 443.

16. Chen, D. L.; Pan, K. L.; Chang, M. B.; J. Environ. Sci. 2017, 56,131 .

17. Liotta, L. F.; Wu, H.; Pantaleo, G.; Venezia, A. M.; Catal. Sci. Technol. 2013, 3, 3085.

18. Deng, H.; Kang, S.; Wang, C.; He, H.; Zhang, C.; Chem. Eng. J. 2018, 348, 361.

19. Fu, X.; Liu, Y.; Yao, W.; Wu, Z.; Catal. Commun. 2016, 83, 22.

20. Xia, Y.; Xia, L.; Liu, Y.; Yang, T.; Deng, J.; Dai, H.; J. Environ. Sci. 2018, 64, 276.

21. Liao, Y.; Jia, L.; Chen, R.; Gu, O.; Sakurai, M.; Kameyama, H.; Zhou, L.; Ma, H.; Guo, Y.; Appl. Catal., A 2016, 522, 32.

22. Rokicińska, A.; Drozdek, M.; Dudek, B.; Gil, B.; Michorczyk, P.; Brouri, D.; Dzwigaj, S.; Kuśtrowski, P.; Appl. Catal., B 2017, $212,59$.

23. Du, J.; Qu, Z.; Dong, C.; Song, L.; Qin, Y.; Huang, N.; Appl. Surf. Sci. 2018, 433,1025.
24. Pan, K. L.; Pan, G. T.; Chong, S.; Chang, M. B.; J. Environ. Sci. 2018, 69, 205.

25. Solsona, B.; Davies, T. E.; Garcia, T.; Vázquez, I.; Dejoz, A.; Taylor, S. H.; Appl. Catal., B 2008, 84, 176.

26. Wang, Z.; Liu, Y.; Yang, T.; Deng, J.; Xie, S.; Dai, H.; Chin. J. Catal. 2017, 38, 207.

27. Rokicińska, A.; Natkański, P.; Dudek, B.; Drozdek, M.; LityńskaDobrzyńska, L.; Kuśtrowski, P.; Appl. Catal., B 2016, 195, 59.

28. Jafari, A. J.; Kakavandi, B.; Jaafarzadeh, N.; Kalantary, R. R.; Ahmadi, M.; Babaei, A. A.; J. Ind. Eng. Chem. 2017, 45, 323.

29. Esmaeilirad, M.; Zabihi, M.; Shayegan, J.; Khorasheh, F.; J. Hazard. Mater. 2017, 333, 293.

30. Pirsaraei, S. R. A.; Mahabadi, H. A.; Jafari, A. J.; J. Porous Mater. 2016, 23, 1015.

31. Schwanke, A. J.; Pergher, S. B.; Probst, L. F.; Balzer, R.; J. Braz. Chem. Soc. 2017, 28, 42.

32. Jafari, S.; Mahabady, H. A.; Kazemian, H.; Catal. Lett. 2009, $128,57$.

33. Güngör, N.; Işçi, S.; Günister, E.; Miśta, W.; Teterycz, H.; Klimkiewicz, R.; Appl. Clay Sci. 2006, 32, 291.

34. Milt, V. G.; Banús, E. D.; Miró, E. E.; Yates, M.; Martín, J. C.; Rasmussen, S. B.; Ávila, P.; Chem. Eng. J. 2010, 157, 530.

35. Liu, S.; Chen, M.; Chu, L.; Yang, Z.; Zhu, C.; Wang, J.; Chen, M.; Int. J. Hydrogen Energy 2013, 38, 3948.

36. Bautista, F. M.; Campelo, J. M.; Luna, D.; Luque, J.; Marinas, J. M.; Catal. Today 2007, 128, 183.

37. Menor, M.; Sayas, S.; Chica, A.; Fuel 2017, 193, 351.

38. Uğurlu, M.; Karaoğlu, M. H.; Chem. Eng. J. 2011, 166, 859.

39. Zhou, C. H.; Li, G. L.; Zhuang, X. Y.; Wang, P. P.; Tong, D. S.; Yang, H. M.; Lin, C. X.; Li, L.; Zhang, H.; Ji, S. F.; Yu, W. H.; Mol. Catal. 2017, 434, 219.

40. Luo, D.; Liu, S.; Liu, J.; Zhao, J.; Miao, C.; Ren, J.; Ind. Eng. Chem. Res. 2018, 57, 11920.

41. Balzer, R.; Probst, L. F. D.; Drago, V.; Schreiner, W.; Fajardo, H. V.; Braz. J. Chem. Eng. 2014, 31, 757.

42. Białas, A.; Mazur, M.; Natkański, P.; Dudek, B.; Kozak, M.; Wach, A.; Kuśtrowski, P.; Appl. Surf. Sci. 2016, 362, 297.

43. Zhao, S.; Hu, F.; Li, J.; ACS Catal. 2016, 6, 3433.

44. Wu, S.; Duan, Z.; Hao, F.; Xiong, S.; Xiong, W.; Lv, Y.; Liu, P.; Luo, H. A.; Dyes Pigm. 2017, 137, 395.

45. Suárez, S.; Yates, M.; Petre, A. L.; Martín, J. A.; Avila, P.; Blanco, J.; Appl. Catal., B 2006, 64, 302.

46. Alalwan, H. A.; Cwiertny, D. M.; Grassian, V. H.; Chem. Eng. J. 2017, 319, 279.

47. Yan, Q.; Li, X.; Zhao, Q.; Chen, G.; J. Hazard. Mater. 2012 , 209-210, 385.

48. de Rivas, B.; López-Fonseca, R.; Jiménez-González, C.; Gutiérrez-Ortiz, J. I.; J. Catal. 2011, 281, 88.

Submitted: January 22, 2019

Published online: May 22, 2019 